\title{
Stem cell self-renewal and recovery of intestinal epithelial barrier dysfunction associated with alcohol abuse
}

\author{
Ichiaki Ito ${ }^{1}$, Sam Jacob ${ }^{2}$, Sumihiro Suzuki ${ }^{3}$, Makiko Kobayashi ${ }^{1}$ and Fujio Suzuki* \\ ${ }^{1}$ Department of Internal Medicine, The University of Texas Medical Branch, Galveston, Texas, USA \\ ${ }^{2}$ Department of Pathology, The University of Texas Medical Branch, Galveston, Texas, USA \\ ${ }^{3}$ Department of Biostatistics and Epidemiology, University of North Texas Health Science Center, Fort Worth, Texas USA
}

\begin{abstract}
In a human gut organoid (HGO) model of alcohol-associated intestinal epithelial barrier dysfunction (EBD), we studied the mechanism of why alcohol-induced EBD is not readily recovered. After exposure to $0.2 \%$ ethanol for 15 days, increased bacterial translocation, decreased villus/crypt ratio, decreased growth rate, and decreased numbers of various epithelial cells were shown in HGOs (alcoholized HGOs, A/HGOs). The intestinal EBD in A/HGOs was persisted for 15 days or more after re-cultivation with alcohol-free fresh media. As compared with HGOs cultured with fresh media (control HGOs, C/HGOs), decreased expression of Ki-67 (a marker of cellular proliferation) and LGR5 (a marker of mitotically active intestinal stem cells) was shown in A/HGOs. Also, Ki-67 and LGR5 were not expressed in C/HGOs previously treated with an inhibitor of Notch signalling. The delayed growth and decreased NOTCH1 mRNA expression and Ki-67 and LGR5 protein levels in $\mathrm{A} / \mathrm{HGOs}$ were restored, at the levels shown in $\mathrm{C} / \mathrm{HGO}$, after co-cultivation with intestinal epithelial cells differentiated from induced pluripotent stem (iPS) cells (iPS-IECs). Minimum bacterial translocation was demonstrated from A/HGOs co-cultured with iPS-IECs, and the decreased ratio of villus/crypt, delayed growth of organoids, and decreased numbers of epithelial cells were restored in A/HGOs co-cultured with iPS-IECs. These results indicate that intestinal EBD associated with alcohol abuse could be repaired through the reactivation of intestinal stem cell self-renewal using iPS-IECs.
\end{abstract}

\section{Introduction}

In the Unites States, nearly 88,000 people die from alcoholattributed diseases each year [1]. Excessive/chronic alcohol consumption causes long lasting intestinal epithelial barrier dysfunction (EBD) which causes various alcohol-attributable diseases, including gastritis, pancreatitis, high blood pressure, cardiovascular diseases (stroke), cirrhosis, dementia, cancers, and gut bacteria-associated systemic infections [2-13]. Loosening tight junctions (manifested by hyperpermeability), reduced antimicrobial peptide/protein secretion (linked to dysbiosis), alcohol-induced epithelial cell death, decreased epithelial regeneration after cell death, impaired intestinal stem cell proliferation, and bacterial translocation are involved in intestinal EBD [2-4,11-16]. Under normal conditions, intestinal epithelial cell injuries (for example, induced by oxidative stress and DNA damage) are easily repaired within 2-3 days after the incidence [2-4]. However, excessive alcohol intake (> $20 \mathrm{~g} /$ day of pure alcohol for years) induces serious intestinal EBD that is not readily repaired $[17,18]$. Intestinal EBD is lasting, at least a month, even when patients with alcohol use disorder (AUD) abstain from alcohol at alcohol rehab facilities [18-20]. Thus, any time during the first month of inpatient hospital stay, AUD patients with intestinal EBD have a risk to catch alcohol-attributable diseases. There is no consensus on the best treatment for intestinal EBD [14,17]. Therefore, a unique strategy to repair intestinal EBD is a critical need in AUD patients.

In this study, using a human gut organoid model of alcoholics, we investigated the mechanism of why alcohol-induced EBD is not readily recovered. Human gut organoids (HGOs) created in our laboratory from induced pluripotent stem (iPS) cells have a recapitulating cryptvillus structure of the intestine, thus stem cells and other epithelial cell lineages are located in appropriate regions of the crypt-villus axis, as seen in adult intestinal tissues [21-27]. In our studies, intestinal EBD has been seriously demonstrated in alcoholized HGOs. However, apoptotic and necrotic cells were not seen in intestinal stem cells and other epithelial cells in alcoholized HGOs $[15,16]$. Given the potential therapeutic advantages of use intestinal epithelial cells differentiated from iPS cells (iPS-IECs), we investigated the repairing effect of iPSIECs on intestinal EBD. For reducing the risk of alcohol-attributable diseases in alcoholics who are seeking recovery in alcohol rehab facilities, iPS-IECs seem to be beneficial for the reactivation of the impaired function of alcoholized stem cells.

\section{Materials and methods}

\section{Ethics}

This study using iPS cells generated form human PBMCs and human gut organoids were approved by Institutional Biosafety Committee of the University of Texas Medical Branch (NOU \#2018030).

\section{Reagents}

Recombinant fibroblast growth factor (FGF) 2, activin A, R-spondin 1, noggin, and epidermal growth factor (EGF) were purchased from PeproTech (Rocky Hill, NJ). Matrigel Matrix

${ }^{\star}$ Correspondence to: Fujio Suzuki, PhD, Department of Internal Medicine, The University of Texas Medical Branch, 301 University Boulevard, Galveston, Texas 77555-0435, USA, Tel: 14097471856, Fax: 14097471856, E-mail: fsuzuki@ utmb.edu

Received: February 22, 2019; Accepted: March 15, 2019; Published: March 22 2019 
Growth Factor Reduced (referred as Matrigel) was purchased from BD Biosciences (Bedford, MA). CD34 ${ }^{+}$Progenitor Reprogramming Kit, RosetteSep cocktail, StemSpan $\mathrm{CD}^{+} 4^{+}$expansion medium, ReproTeSR medium, TeSR medium, Advanced Dulbecco's modified Eagle's medium (DMEM) Ham's nutrient mixture F-12 (DMEM/ F12), fetal bovine serum (FBS), and KnockOut Serum Replacement (KSR) were purchased from STEMCELL Technologies (Vancouver, British Columbia, Canada). Anti-CD34 antibody was purchased from eBioscience (San Diego, CA). High glucose (4,500 mg/L) DMEM, nonessential amino acids (NEAA), L-glutamine (L-Gln), penicillin/ streptomycin, 4',6-Diamidino-2-Phenylindole, Dihydrochloride (DAPI), TRIzol, and SuperScript III First-Strand Synthesis System were purchased from Invitrogen (Carlsbad, CA). Bromoindirubin-30-oxime (BIO), $\quad \mathrm{N}$-[(3,5-Difluorophenyl)acetyl]-L-alanyl-2-phenylglycine1,1-dimethylethyl ester (DAPT), (+)-(R)-trans-4-(1-aminoethyl)$\mathrm{N}$-(4-pyridyl)cyclohexanecarboxamidedihydrochloride (Y-27632), B27 serum-free supplement, leukaemia inhibitory factor (LIF), $\beta$-mercaptoethanol (ME), goat serum, bovine serum albumin (BSA), and FITC-dextran's were purchased from Sigma-Aldrich (St. Louis, MO). Cell Recovery Solution was purchased from Corning (Corning, NY). iTaq Universal SYBR Green Supermix was purchased from BioRad (Hercules, CA). Anti-LGR5 antibody (ab75732) and anti-Ki-67 antibody (ab15580) were purchased form Abcam (Cambridge, MA).

\section{iPS cells generated from peripheral blood $\mathrm{CD}^{2} 4^{+}$cells}

To study the mechanism of why alcohol-induced intestinal EBD is not readily recovered, we utilized human gut organoids (HGOs) and intestinal epithelial cells (iPS-IECs), both of which were differentiated from iPS cells. The iPS cells were generated from $\mathrm{CD} 34^{+}$cells through reprogramming using a $\mathrm{CD} 34^{+}$Progenitor Reprogramming Kit according to the manufacturer's instruction (refer Supplement Chart 1A). Peripheral blood (40-50 mL of buffy coats) from 8 healthy donors was purchased from Gulf Coast Regional Blood Center, Houston, TX. The corresponding protocol was approved by the research ethics board of The University of Texas Medical Branch. To deplete red blood cells, platelets, and lineage-committed cells in the peripheral blood, $50 \mu \mathrm{L}$ of RosetteSep cocktail to $1 \mathrm{~mL}$ of the blood was added, and these cells were separated by SepMate density gradient centrifugation (1200 x g for 10 minutes). Cells in supernatant were collected, washed 2 times with PBS, resuspended with PBS, and added with selection cocktail for $\mathrm{CD}_{4} 4^{+}$cells and RapidSphere particles. CD $34^{+}$cells were magnetically isolated from these cell preparations by positive selection. Routinely, $>1 \times 106$ cells (>97\% viability) were obtained from the buffy coat by this procedure. Obtained CD34 $4^{+}$cells $\left(2.5 \times 10^{4}\right.$ cells $\left./ \mathrm{mL}\right)$ were cultured in StemSpan $\mathrm{CD}_{3} 4^{+}$expansion medium on Matrigel-coated 6-well plate for 7 days. Media were changed every 2 days. The expanded cells were split when they reach a cell density of $5 \times 10^{5}$ cells $/ \mathrm{mL}$ ). Then cells were harvested and resuspended in the same media $\left(1 \times 10^{5}\right.$ cells $\left./ \mathrm{mL}\right)$ supplemented with sendai virus vectors (MOI = 5, CytoTune iPS 2.0 Sendai Reprogramming Kit, ThermoFischer), and cultured for 3 days according to the manufacturer's instructions. Cells $\left(1 \times 10^{5}\right.$ cells $\left./ \mathrm{mL}\right)$ were recultured in StemSpan CD34 $4^{+}$expansion medium for 2 days, then iPS colonies were appeared after cultivation in ReproTeSR medium for 20-30 days. Media were changed every day. iPS cell colonies were fragmented with $21 \mathrm{G}$ needle, scrape, aspirate these colony fragments, and maintained in TeSR medium. iPS cells were stored in liquid nitrogen until further use.

\section{Differentiation of iPS cells to intestinal epithelial cells}

The differentiation of iPS cells to intestinal epithelial cells was performed as previously described $[28,29]$. In brief, iPS cells $\left(5 \times 10^{4}\right.$ cells $/ \mathrm{mL}$ ) were cultured in ES maintenance medium (high glucose DMEM supplemented with LIF, 10\% FBS, 100 mM NEAA, 2 mM L-Gln, 50 units $/ \mathrm{mL}$ penicillin, $50 \mathrm{mg} / \mathrm{mL}$ streptomycin, $100 \mu \mathrm{M} \beta-\mathrm{ME}$, and $10 \mu \mathrm{M}$ Y27632) for 2-3 days on M15 feeder cells that were previously treated with $100 \mu \mathrm{g} / \mathrm{mL}$ of mitomycin $\mathrm{C}$ for 4 hours. The cultured cells were washed with PBS and re-cultured in the first differentiation medium (high glucose DMEM medium supplemented with $2 \%$ B27, $2 \mathrm{mM}$ L-Gln, $100 \mathrm{U} / \mathrm{mL}$ penicillin, $100 \mu \mathrm{g} / \mathrm{mL}$ streptomycin, $100 \mu \mathrm{M}$ $\beta$-Me, and $100 \mathrm{ng} / \mathrm{mL}$ activin A) for 5 days to differentiate into definitive endoderm (DE). Then the culture media was switched to the second differentiation medium (high glucose DMEM medium supplemented with $10 \% \mathrm{KSR}$, glucose 2,000 mg/mL, $2 \mathrm{mM} \mathrm{L}-\mathrm{Gln}, 100 \mathrm{U} / \mathrm{mL}$ penicillin, $100 \mu \mathrm{g} / \mathrm{mL}$ streptomycin, $100 \mu \mathrm{M} \beta-\mathrm{Me}, 5 \mu \mathrm{M}$ BIO, and $10 \mu \mathrm{M}$ DAPT), and cultured for 25 days to differentiate into intestinal epithelial cells. Media were replaced every 2 days with fresh medium. The cells were passaged every 3-4 days. M15 feeder cells were eliminated during the cultivation. The composition of intestinal epithelial cells in iPS-IECs was revealed by flow cytometry 25 days after the second differentiation, as follows: caudal type homeobox $2(\mathrm{CDX} 2)^{+}$cells (enterocytes, $48.8 \%$ ), lysozyme $(\mathrm{LYZ})^{+}$cells (Paneth cells, $\left.13.3 \%\right)$, chromogranin A (CHGA) ${ }^{+}$ cells (enteroendocrine cells, 11.5\%), and dolichos biflorus agglutinin $(\mathrm{DBA})^{+}$cells (goblet cells, 17.1\%) were detected in intestinal epithelial cells (E-cadherin ${ }^{+}$cells) (Supplement Chart 1B and C). These cells were maintained in the second differentiation medium and stored in liquid nitrogen.

\section{Preparation of $\mathrm{C} / \mathrm{HGO}$ and $\mathrm{A} / \mathrm{HGO}$}

Various HGOs were prepared from human iPS cell-derived DE in $3 \mathrm{D}$ cultures (Figure 1A), as previously described [24,25]. DE (50-100 cells), differentiated from iPS cells as described above, was suspended in Matrigel $(50 \mu \mathrm{L})$, and seeded on a pre-warmed 6-well multiwell plate (four $50 \mu \mathrm{L}$ drops/well). The plate was incubated in a $\mathrm{CO}_{2}$ incubator for 15 min to polymerize the Matrigel. The polymerized Matrigel domes were immersed with $3 \mathrm{~mL}$ of organoid culture medium (advanced DMEM/ F12 medium supplemented with $500 \mathrm{ng} / \mathrm{mL}$ R-spondin1, $100 \mathrm{ng} / \mathrm{mL}$ noggin, 100 ng/mL EGF, 2 mM L-Gln, 15 mM HEPES, B27 serumfree supplement, $100 \mathrm{U} / \mathrm{mL}$ penicillin, and $100 \mu \mathrm{g} / \mathrm{mL}$ streptomycin) for 7 days (HGOs, Supplement Chart 2A). Then, HGOs were further cultured with organoid culture medium for 15 days (control HGOs, designated as C/HGOs). The microscopic shape of $\mathrm{C} / \mathrm{HGOs}$ is shown in Supplement Chart 2B. Also, the cellular compositions of $\mathrm{C} / \mathrm{HGO}$ were analysed by flow cytometry, and $\mathrm{CDX}_{2}^{+}$cells $(57.1 \%), \mathrm{CHGA}^{+}$ cells $(16.5 \%), \mathrm{DBA}^{+}$cells $(9.61 \%), \mathrm{LYZ}^{+}$cells $(13.8 \%)$, and LGR5 ${ }^{+}$ cells $(2.63 \%)$ were detected in C/HGOs (Supplement Chart 2C). To prepare HGOs with alcohol-associated EBD (designated as A/HGOs), the HGOs in Matrigel domes were cultured in $0.2 \%(\mathrm{v} / \mathrm{v})$ alcohol for 15 days. The delayed growth was first appeared in HGOs within 6 days of cultivation with $0.2 \%$ ethanol, but not in HGOs cultured with $0.1 \%$ ethanol. Any significant morphological changes and apoptotic cells in the organoids cultured with $0.2 \%$ ethanol were not detected microscopically. During 3D cultivation, media were changed every 2 or 3 days. Cellular components of the organoids were flow cytometrically analyzed for $\mathrm{CDX}^{+}$cells, $\mathrm{LYZ}^{+}$cells, $\mathrm{CHGA}^{+}$cells, $\mathrm{DBA}^{+}$cells, and LGR5 $^{+}$cells.

Before testing their EBD, the Matrigel domes containing C/HGOs or A/HGOs were dissolved by treatment with $2 \mathrm{~mL}$ of Cell Recovery Solution at $4^{\circ} \mathrm{C}$ for 1 hour, then, the organoids in the suspension were washed with PBS. In co-culture experiments, iPS-IECs (5,000 cells) were mixed with A/HGOs (100 organoids) in Matrigel $(50 \mu \mathrm{L})$. The Matrigel domes were cultured in the organoid culture medium for up to 15 days. 
Organoids in the Matrigel culture were isolated using Cell Recovery Solution, washed, and suspended in PBS. Single cells, including iPS-IECs, were excluded from the suspension by using $70 \mu \mathrm{m}$ nylon mesh filter and repeated washing with PBS. Then organoids were subjected to analyses. The growth of organoids was microscopically analysed by measuring area $\left(\mathrm{mm}^{2}\right)$ of the organoids various days after cultivation. Under LEICA DMLB optical microscope (Leica, Wetzlar, Germany) at magnification 200x, the pictures (at least 10 organoids) were taken and area of the organoids was analyzed by ImageJ software. Each experiment was performed in 3-5 different preparations of HGOs.

\section{HGO inoculation in the kidney capsule of humanized mice}

To enlarge C/HGOs, the organoids were engrafted to the kidney capsule of humanized mice [26,30]. Humanized mice are NSG-SGM3 mice 10 to 12 weeks after transplantation with human $\mathrm{CD} 4^{+}$hematopoietic stem cells. A robust human hematopoietic reconstitution in these mice has been previously described [31-33]. Briefly, NSG-SGM3 mice, irradiated with 2.5 Gy $\gamma$-rays 24 hours before inoculation, were i.v. inoculated with $1 \times 10^{4}$ cells/mouse of human CD $34^{+}$hematopoietic stem cells. Using human CD34 MicroBead Kit (Miltenyi Biotec, Auburn, CA), these CD34+ hematopoietic stem cells were magnetically isolated from PBMCs, prepared from healthy donor peripheral blood (Gulf Coast Regional Blood Centre) by Lymphoprep (STEMCELL Technologies) density gradient centrifugation. Ten to twelve weeks after the inoculation, human $\mathrm{CD}^{+}, \mathrm{CD}^{+}, \mathrm{CD} 11 \mathrm{c}^{+}$, and $\mathrm{CD}_{14}{ }^{+}$cells were demonstrated in their circulation. These humanized mice were then grafted with C/HGO under the left kidney capsule (1 HGO/kidney). Grafted C/HGOs (approximately $0.5 \mathrm{~mm}$ diameter) were grown in the kidney of mouse up to 4 weeks after the grafting. Then, the grafted C/HGOs were removed from kidneys. These organoids are designated as kHGOs. Light microscopic image (100x magnification) of the $\mathrm{H} \& \mathrm{E} / \mathrm{kHGO}$ section showed that the kHGOs retained the crypt-villus structure of small intestine (Supplement Chart 2D). Similar to C/HGOs, kHGOs were cultured with (A/kHGOs) or without (C/kHGOs) $0.2 \%$ ethanol for 15 days. In some experiments, $\mathrm{C} /$ kHGOs and A/kHGOs were co-cultured with iPS-IECs ( 1 x $10^{5}$ cells/ organoid/well in 24-well plates) for 15 days on an orbital shaker (100 $\mathrm{rpm}$ ) in a $5 \% \mathrm{CO}_{2}$ incubator. These enlarged organoids were utilized in experiments to determine bacterial translocation, crypt/villi structure, and numbers of various epithelial cells.

kHGOs, iPS-IECs, and immunocompetent cells reconstituted in humanized mice were syngeneic each other.

\section{Intestinal EBD in the A/kHGO co-cultured with or without iPS-IECs}

In the following experiments, at least 5 kHGOs in each group were used.

(i) Bacterial translocation: Each organoid obtained was washed with fresh media 3 times and microinjected with $10^{3} \mathrm{CFU}$ E. faecalis $(10 \mu \mathrm{L})$ using Micro-Cannula needle (BioTime). The number of the pathogen injected to kHGOs was confirmed by the counting of colonies on tryptic soy broth plates $16 \mathrm{~h}$ after cultivation of the organoid homogenates. One to 6 hours after the incubation in antibiotics-free organoid culture medium, aliquots of culture fluids were harvested at each time point, and numbers of the pathogen in the culture fluids of the organoids were measured by a colony counting methods. (ii) Villus/crypt ratio: Organoids obtained were fixed in $4 \%$ paraformaldehyde, paraffin-embedded, sectioned $(5 \mu \mathrm{m})$, and stained with H\&E. Stained sections were analysed under LEICA DMLB optical microscope at magnification 100x (for counting the number of crypts) and 200x (for measuring the length of the villi) in three different filed. The images were captured by a CoolSNAP-Pro digital camera (Media Cybernetics, MD). All measurements were performed with the program AnalySIS Docu (Soft Imaging System GmgH, Munchen, Germany). The number of crypts per field was counted at least 10 microscopic fields of the organoids. The length of the villi was measured from its basal region, which coincided with the top of the crypts. A line was drowning from point on the base toward the point at the apex of the villus. The length of the line provided by the image analyzer was taken as the villus height. From these measurements, the ratio of villus height to crypt depth was calculated.

(iii) Epithelial regeneration: The percentages of $\mathrm{CDX}^{+}$cells (enterocytes), $\mathrm{CHGA}^{+}$cells (enteroendocrine cells), $\mathrm{DBA}^{+}$cells (goblet cells), LYZ ${ }^{+}$cells (Paneth cells), and $\mathrm{LGR}^{+}$cells (stem cells) in the organoids were analyzed by flow cytometry. In some experiments, organoids obtained were analyzed for the mRNA expression of $C D X 2$, CHGA, DBA, LYZ, and LGR5, as shown in "Gene expression analysis" section.

\section{Gene expression analysis}

Organoids in the Matrigel culture were isolated using Cell Recovery Solution, washed, and suspended in PBS. Single cells were excluded from the suspension by using $70 \mu \mathrm{m}$ nylon mesh filter. For gene expression analysis, total RNAs were extracted from organoids with TRIzol reagent according to the manufacturer's instruction. The cDNAs were synthesized with SuperScript III First-Strand Synthesis System. Quantitative real-time PCR was performed using an iTaq Universal SYBR Green Supermix on a ViiA 7 Real-Time PCR System (Applied Biosystems). The expression levels were normalized to that of a housekeeping gene GAPDH. Primer sequences used for real-time PCR analysis are shown in Supplement Table 1.

\section{Western blotting analysis}

Whole cell extracts of the organoids were prepared using a cell extraction buffer, and the supernatants ( $20 \mu \mathrm{g}$ proteins) obtained from the cell extracts were subjected to SDS-PAGE and electrically transferred onto PVDF membranes. Following the blocking with 5\% (w/v) BSA/ TBS-T, the membranes were incubated with anti-LGR5 (dilution rate of $1: 1,000$ ) or anti-Ki-67 (dilution rate of $1: 1,000$ ) antibodies in $1 \%$ (w/v) BSA/TBS-T at $4^{\circ} \mathrm{C}$ overnight. The proteins were detected with secondary antibodies conjugated to HRP using SuperSignal West Pico Chemiluminescent Substrate and X-ray film. The band intensities were densitometrically quantified by ImageJ software and normalized by that of $\beta$-actin for the quantification of protein levels.

\section{Statistical analysis}

For all experiments, $\mathrm{n}$ represents the number of biologic replicates (three-to-four wells were collected for each replicate). Each experiment was repeated on at least three separate occasions (independent experiments) using three-to-five different organoid preparations. Quantified data are represented as mean \pm S.D. Statistical comparisons between two groups were performed using a Student $t$ test. Differences were considered significant at $P<0.05$. 


\section{Results}

\section{Intestinal epithelial barrier dysfunction (EBD) demonstrated in alcoholized organoids}

Intestinal EBD developed in alcoholized kHGOs was investigated. Increased bacterial translocation, reduced villus/crypt ratio, and decreased numbers of various epithelial cells in kHGOs were assayed as typical intestinal EBD markers. kHGOs were cultured with (A/kHGOs) or without (C/kHGOs) $0.2 \%$ ethanol for 15 days. After washing with fresh media, both organoids were microinjected with $10^{3} \mathrm{CFU}$ of $E$. faecalis and cultured for 1 to $6 \mathrm{~h}$. A large number of the pathogen (3 $\mathrm{x} 10^{4} \mathrm{CFU} / \mathrm{mL}$ ) was detected in the culture media of $\mathrm{A} / \mathrm{kHGOs}$ within $3 \mathrm{~h}$ of the cultivation (Figure 1A). However, a minimum number of the pathogen $(12 \mathrm{CFU} / \mathrm{mL}, 3 \mathrm{~h}$ after injection) was detected in the culture fluids of $\mathrm{C} / \mathrm{kHGO}$ microinjected with the same number of $E$. faecalis. In the next experiments, a villus/crypt ratio and the number of various epithelial cells were assessed for $\mathrm{C} / \mathrm{kHGO}$ and $\mathrm{A} / \mathrm{kHGOs}$. As compared with $\mathrm{C} / \mathrm{kHGOs}$, severe damages on the crypts and villi were demonstrated in A/kHGOs (Figure 1B). The length of villi and a villus/crypt ratio in $\mathrm{A} / \mathrm{kHGOs}$ were markedly reduced, as compared to those of $\mathrm{C} / \mathrm{kHGOs}$ (Figure 1C). Also, the percentages of $\mathrm{LYZ}^{+}$cells (Paneth cells) and LGR5 ${ }^{+}$cells (intestinal stem cells) were particularly reduced in $\mathrm{A} / \mathrm{kHGOs}$, rather than that of enterocytes, enteroendocrine cells, and goblet cells, as compared with those of C/kHGOs (Figure 1D). In these experiments, severe intestinal EBD was shown in C/kHGOs exposed to alcohol.

\section{Long lasting EBD in A/HGOs is linked to the inability of intestinal stem cells to proliferate}

A role of the Notch signalling pathway on the intestinal EBD in A/HGOs was investigated. Notch signalling has been described as an essential pathway on the self-renewal of intestinal stem cells [34-36] The propagation of gut epithelial cells is induced through the ability of intestinal stem cells [37-39]. The growth of HGOs was excessively delayed in media added with $0.2 \%$ ethanol, as compared with that of HGOs cultured with alcohol-free medium (Figure 2A). Long lasting EBD in alcoholized HGOs was demonstrated by the growth rate of the organoids, when the organoids were washed out with medium

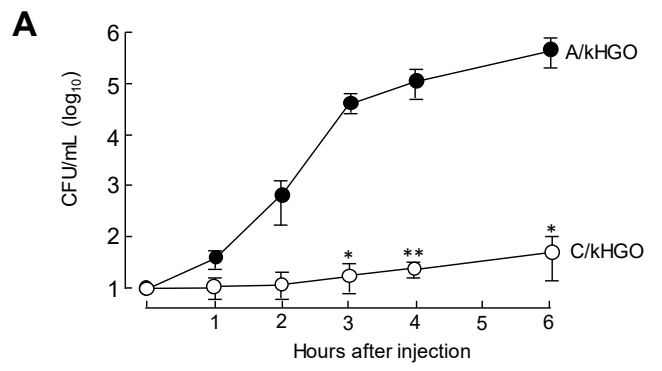

B


\begin{tabular}{clrc} 
D & & & \\
\cline { 2 - 4 } Marker & Cells & C/kHGO & A/kHGO \\
\hline CDX2 & Enterocytes & $63.3 \pm 8.5$ & $58.1 \pm 7.9$ \\
CHGA & Enteroendocrine cells & $13.3 \pm 2.2$ & $11.7 \pm 2.6$ \\
DBA & Goblet cells & $12.8 \pm 6.1$ & $10.1 \pm 2.1$ \\
LYZ & Paneth cells & $8.8 \pm 2.5$ & $3.0 \pm 0.6^{*}$ \\
LGR5 & Stem cells & $3.7 \pm 0.7$ & $0.8 \pm 0.3^{\text {** }}$ \\
\hline
\end{tabular}

Figure 1. Intestinal epithelial barrier dysfunction (EBD) demonstrated in alcoholized kHGOs (A/kHGOs)

A: kHGOs were cultured with (A/kHGOs) or without (C/kHGOs) ethanol $(0.2 \%)$ for 15 days. Both organoids were microinjected with $10^{3} \mathrm{CFU}$ of $E$. faecalis. One to 6 hours after incubation, numbers of the pathogen in the culture fluids of organoids were determined by a colony counting method. B: Light microscopic images (200x magnification) of H\&E stained cross-section of C/kHGOs and A/kHGOs. Bar: $100 \mu \mathrm{m}$. C: From the images shown in B, the number of crypts, villus heights, and crypt depths were measured using ImageJ software, and the ratio of villus height to crypt depth was calculated. D: Epithelial cell markers expressed in $\mathrm{C} / \mathrm{kHGOs}$ and A/kHGOs. The percentages of cells expressing CDX2, CHGA, DBA, LYZ, and LGR5 in the organoids were flow cytometrically analyzed. Data are representative at least two independent experiments. ${ }^{*} P<0.05, * * P<0.01, * * * P<0.001$ 
and recultured with alcohol-free medium. C/HGOs grew up to 2.4fold within 15 days of the cultivation in alcohol-free fresh medium; however, the growth of A/HGOs was limited when they were cultured in the same culture conditions (Figure 2B). Similarly, HGOs treated with DAPT (DAPT/HGOs) did not grow sufficiently. DAPT is an inhibitor of the Notch signalling pathway (Figure 2C). The mRNA expression of NOTCH1 was greatly suppressed in A/HGOs as well as DAPT/HGOs (Figure 2D), indicating that NOTCH1 expression in the organoids is strongly influenced by $0.2 \%$ ethanol. Also, in DAPT/HGOs, the protein levels of Ki-67 (a marker for the cellular proliferation, Figure 2E) and LGR5 (a biomarker of mitotically active intestinal stem cells, Figure $2 \mathrm{~F}$ ) were decreased in the same levels shown by those of A/HGOs. These results indicate that an inability of intestinal stem cells to proliferate and to self-renew is similarly shown in the A/HGOs and DAPT/HGOs.

\section{Improved intestinal EBD in A/HGOs co-cultured with iPS- IECs}

The numbers of intestinal Paneth cells and stem cells were shown to be severely decreased in A/HGOs (see Figure 3D). Paneth cells have been described as an essential cell for the maintenance of stem cell selfrenewal $[34,35]$. Paneth cells activate intestinal stem cells through the activation of Notch signalling under the cell-to-cell interaction [3438]. To recover the intestinal EBD in A/HGOs, we tried to use iPSIECs, because these cells are consisting of 4 different epithelial cells including intact Paneth cells (see Supplement Chart 1) [28,29]. In the first experiment, A/HGOs (100 organoids), co-cultured with or without iPS-IECs (5,000 cells) in fresh alcohol-free media for 3 to 15 days, were assayed for their growth rates (the area of organoids). In the results, the delayed growth of $\mathrm{A} / \mathrm{HGOs}$ was improved when the organoids
A
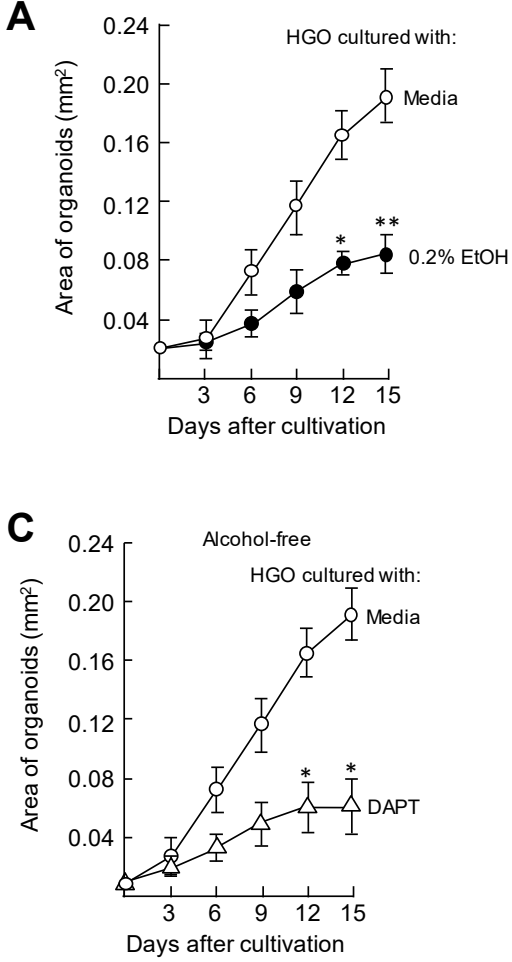

E
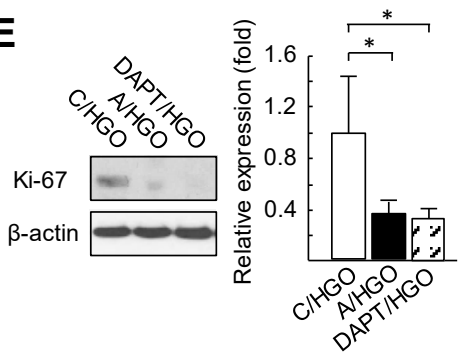

B

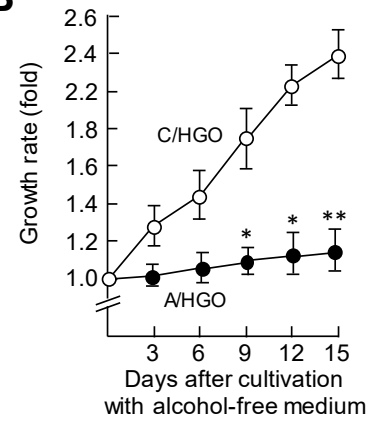

D

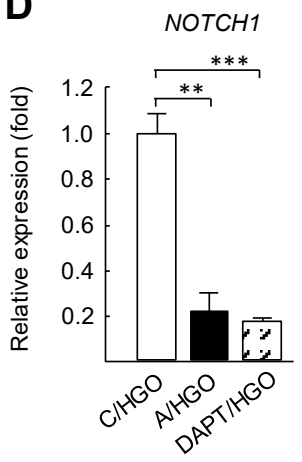

$\mathbf{F}$
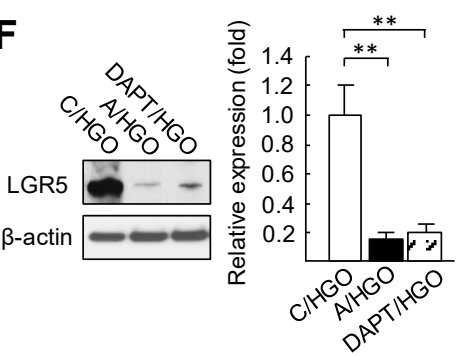

Figure 2. Long lasting EBD in HGOs exposed to alcohol is linked to the inability of intestinal stem cells to proliferate

A: HGOs shown in Figure 1A were 3D cultured with or without $0.2 \%$ ethanol for 15 days. The area $\left(\mathrm{mm}^{2}\right)$ of the organoids was measured by ImageJ software. B: After washing with media at day 15 in cultivation, C/HGOs and A/HGOs were recultured in Matrigel with alcohol-free fresh media for 15 days. The growth rate of the organoids was calculated from the organoid size $\left(\mathrm{mm}^{2}\right)$ measured by ImageJ software. C: HGOs were 3D cultured in media added with or without $10 \mu \mathrm{M}$ DAPT (an inhibitor of the Notch signaling pathway) for 15 days. The area of the organoids was measured by ImageJ software. D: C/HGOs, A/HGOs, and HGOs cultured with DAPT for 15 days (DAPT/HGOs) were analyzed for the NOTCH1 mRNA expression by real-time PCR. E (Ki-67) and F (LGR5): the protein levels in C/HGOs, A/HGOs, and DAPT/HGOs were assayed by Western blotting. The protein levels were quantified by densitometric analysis. Data are representative at least three independent experiments. ${ }^{*} P<0.05,{ }^{* *} P<0.01$ 
A

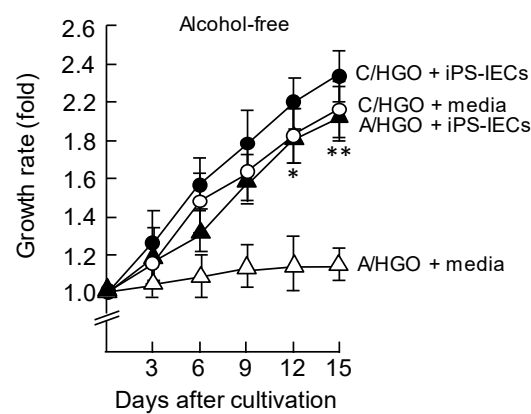

B

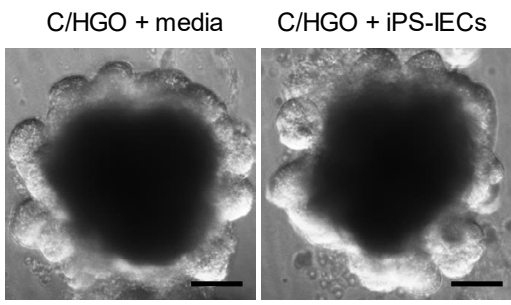

$\mathrm{A} / \mathrm{HGO}+$ media

$\mathrm{A} / \mathrm{HGO}+\mathrm{iPS}-\mathrm{IECS}$

C

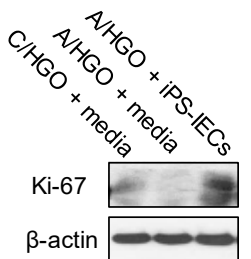

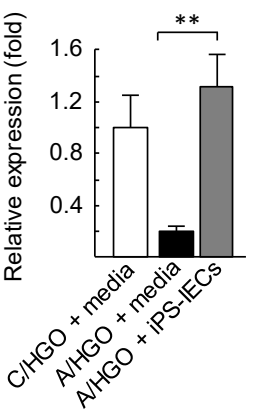
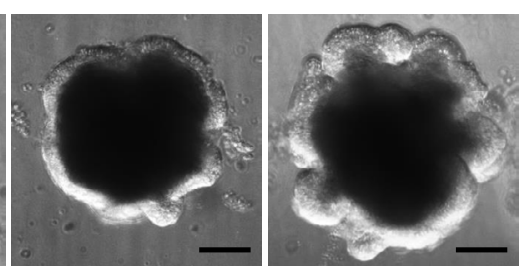

D
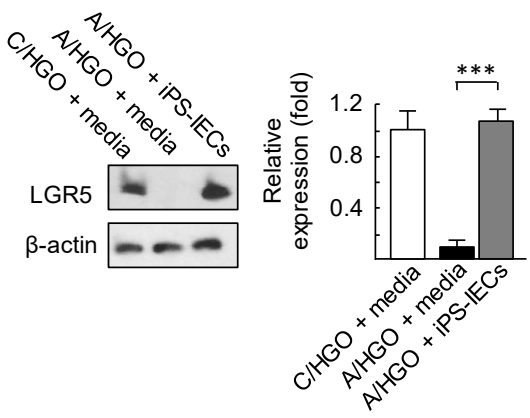

Figure 3. Effect of iPS-IECs on the intestinal EBD developed in alcoholized HGOs

A: C/HGOs and A/HGOs were co-cultured with or without iPS-IECs for an additional 3 to 15 days in alcohol-free fresh medium. The growth rates were calculated from the area of the organoids measured with ImageJ software and the growth rates were shown. B: Microscopic morphologies of these organoids at day 15 in cultivation were shown. C (Ki-67) and D (LGR5): the same organoids were analyzed for protein levels by Western blotting. The protein levels were quantified by densitometric analysis. Data are representative at least three independent experiments. $* P<0.05, * * P<0.01, * * * P<0.001$

were co-cultured with iPS-IECs (Figure 3A). This was confirmed by the morphology of A/HGOs 15 days after the co-cultivation with iPSIECs (Figure 3B). In the same cultures, the growth of C/HGOs was not influenced by iPS-IECs added (Figure 3A). Furthermore, the protein levels of Ki-67 and LGR5 in the A/HGOs co-cultured with iPS-IECs were recovered to the levels shown in intact C/HGOs (Figure $3 \mathrm{C}$ and D). These results indicate that intestinal stem cells in $\mathrm{A} / \mathrm{HGOs}$ are reactivated after co-cultivation with iPS-IECs.

In the next experiments, the effect of iPS-IECs on the intestinal EBD in $\mathrm{A} / \mathrm{HGOs}$ was examined. In the first step, the bacterial translocation from $\mathrm{A} / \mathrm{kHGOs}$ microinjected with $E$. faecalis was tested after the cocultivation with iPS-IECs. Increased numbers of the pathogen were demonstrated in the culture fluids of A/HGOs (Figure 4A). However, the numbers of the pathogen were shown to be a minimum in culture fluids of $\mathrm{A} / \mathrm{kHGOs}$ previously co-cultured with iPS-IECs. Also, the damaged villus structures were recovered in A/HGOs co-cultured with iPS-IECs (Figure 4B). The length of villi and a villus/crypt ratio of these organoids were markedly restored, as compared to those of $\mathrm{A} / \mathrm{kHGOs}$ cultured with Media (Figure 4C). The reduced expression of CDX2,
CHGA, DBA, LYZ, and LGR5 mRNAs was recovered in A/kHGOs cocultured with iPS-IECs (Figure 4D). Particularly, the decreased mRNA expression of $L Y Z$ (a Paneth cell marker) and LGR5 (a mitotically active stem cell marker) was improved in A/kHGOs after co-cultivation with iPS-IECs (Figure 4D). These results indicate that iPS-IECs are effective on the repair of intestinal EBD developed in A/HGOs.

\section{Discussion}

Alcohol abuse causes long lasting intestinal epithelial barrier dysfunction (EBD) which is the cause of various alcohol-attributable diseases [2-4]. Intestinal EBD induced by oxidative stress or DNA damage is usually repaired within 2-3 days [2-4]. However, intestinal EBD developed under chronic alcohol abuse is not readily repaired, even when the patients abstain from alcohol at alcohol rehab facilities [1720]. In this study, using a human gut model of alcoholics (alcoholized human gut organoid), we tried to control intestinal EBD caused by alcohol. Increased bacterial translocation, decreased villus/crypt ratio, and decreased epithelial regeneration were demonstrated in human gut organoids exposed to $0.2 \%$ ethanol for 15 days (A/HGOs), without 
A

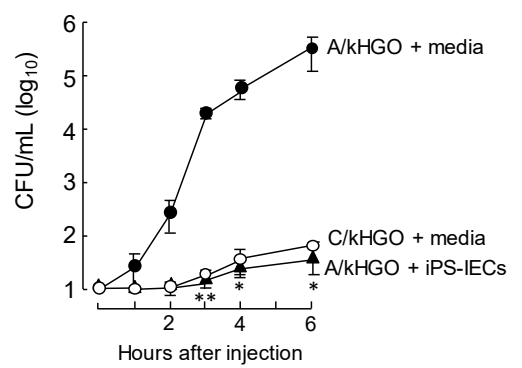

B

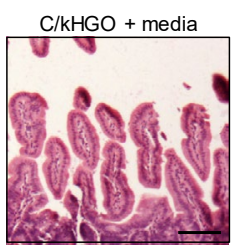

$\mathrm{A} / \mathrm{kHGO}+$ media

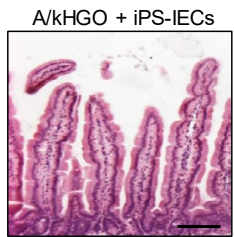

C

\begin{tabular}{lcccc}
\hline & \multicolumn{2}{c}{ Crypts } & & \multicolumn{2}{c}{\begin{tabular}{l} 
Villus height \\
\cline { 2 - 5 }
\end{tabular}} & number/field & depth $(\mu \mathrm{m})$ & Villus height $(\mu \mathrm{m})$ & /crypt depth \\
\hline $\mathrm{C} / \mathrm{kHGO}+$ media & $10.71 \pm 1.02$ & $65.5 \pm 11.8$ & $312.9 \pm 10.1$ & $5.20 \pm 0.55$ \\
$\mathrm{~A} / \mathrm{kHGO}+$ media & $7.18 \pm 2.35$ & $69.1 \pm 11.7$ & $169.8 \pm 13.4$ & $2.97 \pm 0.77$ \\
$\mathrm{~A} / \mathrm{kHGO}+$ iPS-IECs & $11.76 \pm 2.18$ & $64.1 \pm 14.1$ & $329.2 \pm 31.1^{\text {** }}$ & $5.54 \pm 0.99^{*}$ \\
\hline
\end{tabular}

D

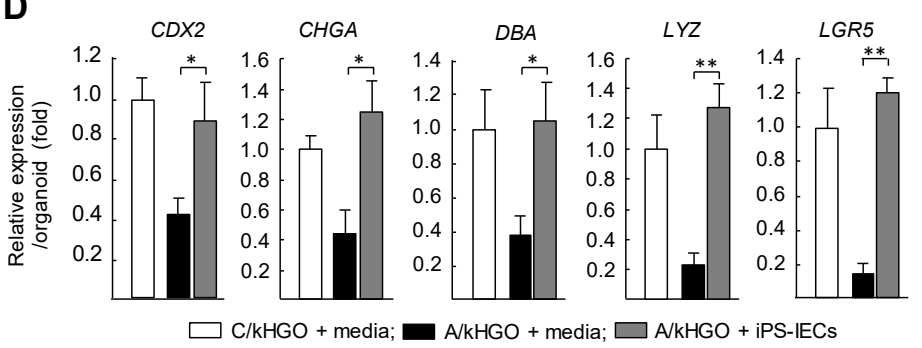

Figure 4. Improved intestinal EBD in A/HGOs co-cultured with iPS-IECs

$\mathrm{C} / \mathrm{kHGOs}$ and $\mathrm{A} / \mathrm{kHGOs}$ were co-cultured with or without iPS-IECs $\left(1 \times 10^{5}\right.$ cells) for 15 days in a fresh alcohol-free medium. A: The organoid harvested were microinjected with $10^{3} \mathrm{CFU}$ of E. faecalis. One to 6 hours after incubation, numbers of the pathogen in culture fluids of organoids were determined by a colony counting method. B: Light microscopic images (200x magnification) of H\&E stained cross-section of the organoids. Bar: $100 \mu \mathrm{m}$. C: From the images shown in B, the number of crypts, villus heights, and crypt depths were measured using ImageJ software, and the ratio of villus height to crypt depth was calculated. D: C/kHGOs and A/kHGOs co-cultured with or without iPS-IECs were analyzed for the mRNA expression of epithelial cell markers $(C D X 2, C H G A, D B A, L Y Z$, and $L G R 5)$ by real-time PCR. mRNA abundance relative to that of GAPDH per an organoid is shown. Data are representative at least two independent experiments. $* P<0.05, * * P<0.01$

any significant increase of apoptotic or necrotic cells. These EBD was persisted for 15 days or more after the A/HGOs were re-cultured with alcohol-free fresh 3D culture medium. This was shown to be linked to the inability of intestinal stem cells to self-renew, because the delayed growth and reduced Ki-67 and LGR5 protein levels were demonstrated in HGOs treated with an inhibitor of the Notch signalling pathway, similar to those shown in A/HGOs. The expression of Notch signal target genes, such as OLFM4 and HES1, was decreased in A/HGOs (data not shown). The delayed growth, reduced NOTCH1 expression, and decreased Ki-67 and LGR5 protein levels were improved in A/ HGOs co-cultured with iPS-IECs. Bacterial translocation was shown to be minimal in A/HGOs co-cultured with iPS-IECs, and the decreased ratio of villus/crypt and decreased epithelial regeneration were improved in A/HGOs co-cultured with iPS-IECs. These results indicate that intestinal EBD associated with alcohol abuse could be restored through the reactivation of intestinal stem cell self-renewal, and iPS-IECs are shown to be a good tool to reactivate intestinal stem cells influenced by alcohol. Intestinal stem cells are located adjacent to Paneth cells, in a permissive microenvironment within the first 4 to 5 cell positions from the bottom of the crypt, with some intestinal stem cells interspersed among the Paneth cells. The G protein-coupled receptor LGR5 is capable of supporting regeneration of the intestinal epithelium [37-39]. LGR5 expression in the intestinal stem cells is largely dependent on the activation of Notch signalling that is stimulated by Paneth cells through cell-cell interaction [34-36]. When Notch ligands [delta-like (DLL) 1 or 4] bind to Notch receptors, the Notch receptors are cleaved to 2 parts by $\gamma$-secretase, and the Notch intracellular domain (NICD) translocate to the nucleus $[36,40]$. NICD then binds with the RBP-Jк family to initiate transcription of Notch downstream target genes [36,40]. Genetic depletion of Notch pathway components, including the crucial Notch DNA-binding protein RBP-J $\kappa$, Notch receptors or DLL ligands, causes the decreased cellular proliferation in the intestinal crypts together with secretory cell hyperplasia [41-43]. The decreased cellular proliferation in the intestinal stem cells has been observed in rodents after treatment with $\gamma$-secretase inhibitors which block the cleavage of Notch receptors $[42,44,45]$. In our results, a protein level of LGR5 was decreased in $\mathrm{A} / \mathrm{HGOs}$, and it was restored in the organoids co-cultured with iPSIECs, however, the integration of iPS-IECs into A/HGOs was not 
demonstrated in our preliminary experiments. The results obtained in this study indicate that intestinal EBD in A/HGOs could be restored by iPS-IECs; however, we do not know how intestinal stem cells are reactivated in A/HGOs co-cultured with iPS-IECs. Generally, epithelial regeneration is fuelled by intestinal stem cells that give rise to daughter or progenitor cells, which can subsequently differentiate into the mature enterocytes, enteroendocrine cells, goblet cells and Paneth cells [37-39]. Thus, a reactivation of Notch signalling in intestinal stem cells of A/ HGOs results in the improvement of intestinal EBD. Impaired Notch signalling in intestinal stem cells of A/HGOs may be reactivated by Paneth cells, a component of iPS-IECs, because decreased LGR5 levels is restored in $\mathrm{A} / \mathrm{HGO}$ co-cultured with iPS-IECs. We anticipate that intestinal EBD in A/HGOs will be efficiently restored if the organoids are co-cultured with Paneth cell alone. On the other hands, various signalling pathways activated in response to growth factors (such as Wnt, transforming growth factor $\beta$, and bone morphogenetic protein pathways) have been shown to be involved in homeostasis of intestinal epithelial cells [46]. Also, EGF and transforming growth factor a have been described as an intestinal epithelial cell mitogen $[46,47]$. Therefore, certain soluble growth factors produced by iPS-IECs may have a possibility to support the regeneration of epithelial cells of A/ HGOs. To clarify the mechanism by which iPS-IECs improve alcoholinduced intestinal EBD by reactivating the self-renewal of intestinal stem cells, further studies are required.

In this study, as a model of intestinal EBD of alcoholics, we created alcohol-induced intestinal EBD in human gut organoids (A/HGOs). Because the organoids have a recapitulating crypt-villus structure of the intestine, we think that $\mathrm{C} / \mathrm{HGO}$ and $\mathrm{A} / \mathrm{HGOs}$ are beneficial to develop analytical studies for intestinal EBD of AUD patients focusing on the alcohol-induced damages of intestinal stem cells and other intestinal epithelial cell lineages. In fact, alcoholized murine intestinal organoids have been utilized in some papers, as a model of the small intestine with alcohol abuse $[15,16]$. In previous papers using murine intestinal organoids, through the impairing Notch and Wnt/ $\beta$-catenin pathway, the intestinal stem cell homeostasis has been demonstrated to be greatly suppressed by alcohol $[15,16]$.

As one of intestinal EBD markers, loosening tight junctions have been studied in many papers using intestinal cell monolayers [48-50]. Ethanol and its metabolite (acetaldehyde) disrupt epithelial tight junction integrity [51]. In our recent studies, the expression of tight junction proteins (ZO-1 and OCLN) was reduced in A/HGOs (Supplement Chart 3A and B). After co-cultivation with iPS-IECs, decreased expression of tight junction proteins in $\mathrm{A} / \mathrm{HGOs}$ recovered (Supplement Chart 3A and B). Although loosening tight junction is one of the possible routes of bacterial translocation, we think that the repairing the loosening tight junction by iPS-IECs is not directly linked to the inhibition of bacterial translocation from $\mathrm{A} / \mathrm{HGO}$ microinjected with E. faecalis. In our studies, increased FITC-dextran leakage from A/ HGOs was demonstrated when $\mathrm{A} / \mathrm{HGO}$ was microinjected with $4 \mathrm{kDa}$ or $10 \mathrm{kDa}$ FITC-dextran (Supplement Chart 4A). However, 40 and 70 $\mathrm{kDa}$ FITC-dextrans were not leaked from the A/HGOs (Supplement Chart 4B). Molecular sizes of these dextrans are $4.62 \mathrm{~nm}$ (40 kDa FITCdextran) and $5.79 \mathrm{~nm}$ (70 kDa FITC-dextran). Because the size of $E$. faecalis (used in our experiments) is $0.5-1.0 \mu \mathrm{m}$, the translocation of the pathogen out of the A/HGOs microinjected with $E$. faecalis seems to occur predominantly via transcellular route. Therefore, we consider that the increased E. faecalis translocation from A/HGOs is not simply depended on the permeability increased in A/HGOs. Generally, gutassociated bacterial translocation occurs by an increased number of microbiota, reduced mucin layers, and suppressed immune responses in the translocation sites, and bacterial translocation routinely causes via transcellular routs (mainly through $\mathrm{M}$ cells) [52,63]. Therefore, further studies are needed to clarify the mechanism of action how iPSIECs suppress the bacterial translocation from A/HGOs.

In conclusion, alcohol-induced intestinal EBD in human gut organoids was shown to be improved through the reactivation of intestinal stem cell self-renewal by iPS-IECs. For the reactivation of alcoholized intestinal stem cells (or to improve intestinal EBD caused by alcohol), iPS-IECs are suggested to be beneficial and advantageous, because, in our murine studies, intestinal epithelial cells created from embryonic stem cells were shown to be homed to villi and crypts in the small intestine after i.v. inoculation in chronic alcohol-consuming mice. iPS-IECs may have a possibility to reduce the risk of alcoholattributable diseases in alcoholics who is seeking recovery in alcohol rehab facilities.

\section{Conflicts of interest}

The authors have no financial or personal relationship that could cause a conflicts of interest regarding this article.

\section{References}

1. Centers for Disease Control and Prevention (CDC). Alcohol and public health Alcohol-Related Disease Impact (ARDI). Average for United States 2006-2010 Alcohol-attributable deaths due to excessive alcohol use.

2. Purohit V, Bode JC, Bode C, Brenner DA, Choudhry MA, et al. (2008) Alcohol, intestinal bacterial growth, intestinal permeability to endotoxin, and medical consequences: summary of a symposium. Alcohol 42: 349-361.

3. Bode C, Bode JC (2003) Effect of alcohol consumption on the gut. Best Pract Res Clin Gastroenterol 17: 575-592. [Crossref]

4. Elamin EE, Masclee AA, Dekker J, Jonkers DM (2013) Ethanol metabolism and its effects on the intestinal epithelial barrier. Nutr Rev 71: 483-499. [Crossref]

5. Uppal R, Lateef SK, Korsten MA, Paronetto F, Lieber CS (1991) Chronic alcoholic gastritis. Roles of alcohol and Helicobacter pylori. Arch Intern Med 151: 760-764

6. Yadav D (2016) Reassessing the risk of pancreatitis with alcohol. Pancreas 45: 781 782. [Crossref]

7. Estruch R, Coca A, Rodicio JL (2005) High blood pressure, alcohol and cardiovascular risk. J Hypertens 23: 226-229. [Crossref]

8. Klatsky AL (2007) Alcohol, cardiovascular diseases and diabetes mellitus. Pharmacol Res 55: 237-247.

9. Sharp LK, Mallya M, Kinghorn KJ, Wang Z, Crowther DC, (2006) Sugar and alcoho molecules provide a therapeutic strategy for the serpinopathies that cause dementia and cirrhosis. FEBS J 273: 2540-2552.

10. Vanella G, Archibugi L, Stigliano S, Capurso G (2019) Alcohol and gastrointestinal cancers. Curr Opin Gastroenterol 35: 107-113. [Crossref]

11. Yan AW, Schnabl B (2012) Bacterial translocation and changes in the intestinal microbiome associated with alcoholic liver disease. World J Hepatol 4: 110-118.

12. Tuomisto S, Pessi T, Collin P, Vuento R, Aittoniemi J, (2014) Changes in gut bacterial populations and their translocation into liver and ascites in alcoholic liver cirrhotics. BMC Gastroenterol 14: 40.

13. Tabata T, Tani T, Endo Y, Hanasawa K (2002) Bacterial translocation and peptidoglycan translocation by acute ethanol administration. J Gastroenterol 37:726-731.

14. Sarin SK, Pande A, Schnabl B (2019) Microbiome as a therapeutic target in alcoholrelated liver disease. J Hepatol 70: 260-272. [Crossref]

15. Lu R, Voigt RM, Zhang Y, Kato I, Xia Y, et al. (2017) Alcohol injury damages intestinal stem cells. Alcohol Clin Exp Res 41: 727-734. [Crossref]

16. Di Rocco G, Baldari S, Pani G, Toietta G (2019) Stem cells under the influence of alcohol: effects of ethanol consumption on stem/progenitor cells. Cell Mol Life Sci 76 : 231-244. [Crossref]

17. Akbar M, Egli M, Cho YE, Song BJ, Noronha A (2018) Medications for alcohol use disorders: An overview. Pharmacol Ther 185: 64-85. [Crossref] 
18. Gao J, Cao J, Guo T, Xiao Y (2018) Association between alcoholic interventions and abstinence rates for alcohol use disorders: A meta-analysis. Medicine (Baltimore) 97 e13566. [Crossref]

19. Marchesi C1, Chiodera P, Brusamonti E, Volpi R, Coiro V (1997) Abnormal plasma oxytocin and beta-endorphin levels in alcoholics after short- and long-term abstinence. Prog Neuropsychopharmacol Biol Psychiatry 21: 797-807. [Crossref]

20. Mutlu EA, Gillevet PM, Rangwala H, Sikaroodi M, Naqvi A, et al (2012) Colonic microbiome is altered in alcoholism. Am J Physiol Gastrointest Liver Physiol 302: G966-978.

21. Wallach TE, Bayrer JR (2015) Intestinal organoids: new frontiers in the study of intestinal disease and physiology. J Pediatr Gastroenterol Nutr 64: 180-185.

22. Bartfeld S, Clevers H (2017) Stem cell-derived organoids and their application for medical research and patient treatment. J Mol Med (Berl) 95: 729-738. [Crossref]

23. Sato T, Clevers H (2015) SnapShot: Growing Organoids from Stem Cells. Cell 161 1700-1700. [Crossref]

24. Onozato D, Yamashita M, Nakanishi A, Akagawa T, Kida Y, et al. (2018) Generation of intestinal organoids suitable for pharmacokinetic studies from human induced pluripotent stem cells. Drug Metab Dispos 46: 1572-1580. [Crossref]

25. Workman MJ, Gleeson JP, Troisi EJ, Estrada HQ, Kerns SJ, et al. (2017) Enhanced utilization of induced pluripotent stem cell-derived human intestinal organoids using microengineered chips. Cell Mol Gastroenterol Hepatol 5: 669-677. [Crossref]

26. Dedhia PH, Bertaux-Skeirik N, Zavros Y, Spence JR (2016) Organoid models of human gastrointestinal development and disease. Gastroenterology 150: 1098-1112. [Crossref]

27. Karve SS, Pradhan S, Ward DV, Weiss AA (2017) Intestinal organoids model human responses to infection by commensal and Shiga toxin producing Escherichia coli. PLoS One 12: e0178966. [Crossref]

28. Ogaki S, Shiraki N, Kume K, Kume S (2013) Wnt and notch signals guide embryonic stem cell differentiation into the intestinal lineages. Stem Cells 31: 1086-1096. [Crossref]

29. Ozawa T, Takayama K, Ryota O, Ryosuke N, Fuminori S, et al. (2015) Generation of enterocyte-like cells from human induced pluripotent stem cells for drug absorption and metabolism studies in human small intestine. Sci Rep 5: 16479. [Crossref]

30. Mahe MM, Brown NE, Poling HM, Helmrath MA (2017) In vivo model of small intestine. Methods Mol Biol 1597: 229-245. [Crossref]

31. Theocharides AP, Rongvaux A, Fritsch K, Flavell RA, Manz MG (2016) Humanized hemato-lymphoid system mice. Haematologica 101: 5-19. [Crossref]

32. Billerbeck E, Barry WT, Mu K, Dorner M, Rice CM, et al. (2011) Development of human $\mathrm{CD} 4+\mathrm{FoxP} 3+$ regulatory $\mathrm{T}$ cells in human stem cell factor-, granulocytemacrophage colony-stimulating factor-, and interleukin-3-expressing NOD-SCID IL2R? (null) humanized mice. Blood 117: 3076-3086.

33. Bryce PJ, Falahati R, Kenney LL, Leung J, Bebbington C, et al. (2016) Humanized mouse model of mast cell-mediated passive cutaneous anaphylaxis and passive systemic anaphylaxis. J Allergy Clin Immunol 138: 769-779. [Crossref]

34. VanDussen KL, Carulli AJ, Keeley TM, Patel SR, Puthoff BJ, et al. (2012) Notch signalling modulates proliferation and differentiation of intestinal crypt base columnar stem cells. Development 139: 488-497.

35. Carulli AJ, Keeley TM, Demitrack ES, Chung J, Maillard I, et al. (2015) Notch receptor regulation of intestinal stem cell homeostasis and crypt regeneration. Dev Biol 402: 98-108. [Crossref]

36. Barker N, van Es JH, Kuipers J, Kujala P, van den Born M, et al. (2007) Identification of stem cells in small intestine and colon by marker gene Lgr5. Nature 449: 1003-1007. [Crossref]

37. Umar S (2010) Intestinal stem cells. Curr Gastroenterol Rep 12: 340-348. [Crossref]

38. Sailaja BS, He XC, Li L (2016) The regulatory niche of intestinal stem cells. J Physiol 594: 4827-4836. [Crossref]

39. Andersson ER, Lendahl U (2014) Therapeutic modulation of notch signalling--are we there yet? Nat Rev Drug Discov 13: 357-378. [Crossref]

40. Fortini ME (2009) Notch signalling: the core pathway and its posttranslational regulation. Dev Cell 16: 633-647. [Crossref]

41. van Es JH, van Gijn ME, Riccio O, van den Born M, Vooijs M, et al. (2005) Notch/ gamma-secretase inhibition turns proliferative cells in intestinal crypts and adenomas into goblet cells. Nature 435: 959-963.
42. Riccio O, van Gijn ME, Bezdek AC, Pellegrinet L, van Es JH, et al. (2008) Loss of intestinal crypt progenitor cells owing to inactivation of both Notch1 and Notch2 is accompanied by derepression of CDK inhibitors p27Kip1 and p57Kip2. EMBO Rep 9: $377-383$.

43. Pellegrinet L, Rodilla V, Liu Z, Chen S, Koch U, et al. (2011) Dll1- and dll4-mediated notch signaling are required for homeostasis of intestinal stem cells. Gastroenterology 140: $1230-1240$. [Crossref]

44. Milano J, McKay J, Dagenais C, Foster-Brown L, Pognan F, et al. (2004) Modulation of notch processing by gamma-secretase inhibitors causes intestinal goblet cell metaplasia and induction of genes known to specify gut secretory lineage differentiation. Toxicol Sci 82: $341-358$.

45. Wong GT, Manfra D, Poulet FM, Zhang Q, Josien H, et al. (2004) Chronic treatment with the gamma-secretase inhibitor LY-411,575 inhibits beta-amyloid peptide production and alters lymphopoiesis and intestinal cell differentiation. $J$ Biol Chem 279: $12876-12882$.

46. Jeon MK, Klaus C, Kaemmerer E, Gassler N (2013) Intestinal barrier: molecular pathways and modifiers. World J Gastrointest Pathophysiol 4: 94-99.

47. Frey MR, Golovin A, Polk DB (2004) Epidermal growth factor-stimulated intestinal epithelial cell migration requires Src family kinase-dependent p38 MAPK signaling. $J$ Biol Chem 279: 44513-44521.

48. Fukui H (2016) Increased intestinal permeability and decreased barrier function: Does it really influence the risk of inflammation? Inflamm Intest Dis 1: 135-145. [Crossref]

49. König J, Wells J, Cani PD, García-Ródenas CL, MacDonald T, et al. (2016) Human intestinal barrier function in health and disease. Clin Transl Gastroenterol 7: e196. [Crossref]

50. Liang GH, Weber CR (2014) Molecular aspects of tight junction barrier function. Curr Opin Pharmacol 19: 84-89.

51. Elamin E, Jonkers D, Juuti-Uusitalo K, van Ijzendoorn S, Troost F, et al. (2012) Effects of ethanol and acetaldehyde on tight junction integrity: in vitro study in a threedimensional intestinal epithelial cell culture model. PLoS One 7: e35008.

52. Slyepchenko A, Maes M, Jacka FN, Köhler CA, Barichello T, et al. (2017) Gut microbiota, bacterial translocation, and interactions with diet: pathophysiological links between major depressive disorder and non-communicable medical comorbidities. Psychother Psychosom 86: 31-46. [Crossref]

53. Andersen K, Kesper MS, Marschner JA, Konrad L, Ryu M, et al. (2017) Intestinal dysbiosis, barrier dysfunction, and bacterial translocation account for ckd-related systemic inflammation. J Am Soc Nephrol 28: 76-83. [Crossref]

54. Schroeder BO (2019) Fight them or feed them: how the intestinal mucus layer manages the gut microbiota. Gastroenterol Rep (Oxf) 7: 3-12. [Crossref]

55. Vega-MagaÃ $\pm a$ N1, Delgado-Rizo V2, GarcÃa-Benavides L3, Del Toro-Arreola S1, Segura-Ortega J4, et al. (2018) Bacterial translocation is linked to increased intestinal IFN-I $\hat{I}^{3}$, IL-4, IL-17, and mucin-2 in cholestatic rats. Ann Hepatol 17: 318-329. [Crossref]

56. Tsuchimoto Y, Asai A, Tsuda Y, Ito I, Nishiguchi T, et al. (2015) M2b monocytes provoke bacterial pneumonia and gut bacteria-associated sepsis in alcoholics. $J$ Immunol 195: 5169-5177.

57. Ohama H, Asai A, Ito I, Suzuki S, Kobayashi M, et al. (2015) M2b macrophage elimination and improved resistance of mice with chronic alcohol consumption to opportunistic infections. Am J Pathol 185: 420-431.

58. Kobayashi M, Asai A, Ito I, Suzuki S, Higuchi K, et al. (2017) Short-term alcohol abstinence improves antibacterial defenses of chronic alcohol-consuming mice against gut bacteria-associated sepsis caused by enterococcus faecalis oral infection. $\mathrm{Am} J$ Pathol 187: 1998-2007. [Crossref]

59. Suzuki F, Loucas BD, Ito I, Asai A, Suzuki S, et al. (2018) Survival of mice with gastrointestinal acute radiation syndrome through control of bacterial translocation. $J$ Immunol 201: 77-86. [Crossref]

60. Kobayashi M, Nakamura K, Cornforth M, Suzuki F (2012) Role of M2b macrophages in the acceleration of bacterial translocation and subsequent sepsis in mice exposed to whole body [137Cs] ?-irradiation. J Immunol 189: 296-303.

61. Ito I, Bhopale KK, Kobayashi M (2017) Lamina propria group 2 innate lymphoid cells impair the antibacterial defense of burned mice to enterococcal translocation. $J$ Leukoc Biol 102: 1451-1460. [Crossref] 
62. Tahoun A, Siszler G, Spears K, McAteer S, Tree J, et al. (2011) Comparative analysis of EspF variants in inhibition of Escherichia coli phagocytosis by macrophages and inhibition of E. coli translocation through human- and bovine-derived $\mathrm{M}$ cells. Infect Immun 79: 4716-4729.
63. Bermudez LE, Petrofsky M, Sommer S, Barletta RG (2010) Peyer's patch-deficient mice demonstrate that Mycobacterium avium subsp. paratuberculosis translocates across the mucosal barrier via both $\mathrm{M}$ cells and enterocytes but has inefficient dissemination. Infect Immun 78: 3570-3577.

Copyright: (2019 Ito I. This is an open-access article distributed under the terms of the Creative Commons Attribution License, which permits unrestricted use, distribution, and reproduction in any medium, provided the original author and source are credited. 